\title{
Hombres de cuidado ien emergencia! Los Cuidados y masculinidades en el actual contexto COVID-19 en Centroamérica
}

\author{
Men of care, in an emergency! Care and masculinities in the \\ current context of COVID-19 in Central-America
}

Larry José Madrigal Rajo*

Walberto V. Tejeda Guardado*

\begin{abstract}
Resumen
La pandemia del COVID-19 ha develado una profunda crisis de los cuidados en Centroamérica. Las cifras de contagios y decesos parecen afectar más a los hombres, especialmente jóvenes y urbanos y la carga de cuidados sobre la mujeres aumenta y se complejiza. Los reportes e informes provenientes de medios de comunicación, redes virtuales y de grupos organizados de la sociedad civil en Guatemala, Honduras, El Salvador y Nicaragua indican comportamientos de los hombres que no están ayudando a la prevención, contención y educación frente al virus. En toda la situación se evidencia un insuficiente abordaje de género y casi nula interseccionalidad y ausencia de enfoque de masculinidades. Este artículo analiza la situación regional con lentes de género desde la acción y reflexión política del Programa de Masculinidades, problematizando las cifras y datos, discutiendo la crisis de los cuidados y potenciando la corresponsabilidad de los hombres desde una opción profeminista.
\end{abstract}

Palabras clave: Masculinidades, Cuidados, Corresponsabilidad de los varones, COVID19, Centroamérica.

\begin{abstract}
The COVID-19 pandemic has unveiled a deep care crisis in Central America. The numbers of infections and deaths seem to affect mainly men, especially young and urban,

*Ingeniero en Ciencias Agronómicas, Licenciado en Teología, Maestría en Literatura Bíblica especializado en Ciencias Bíblicas. Investigador y facilitador regional, Iniciativa Masculinidades, género y religión, Programa de Masculinidades, Centro Bartolomé de las Casas, San Salvador. Correo electrónico: larrymadrigal.cbc@gmail.com

** Filósofo, Maestría en Política y Evaluación Educativa. Investigador y facilitador regional Iniciativa Procuidados, Programa de Masculinidades, Centro Bartolomé de las Casas, San Salvador. Correo electrónico: tejedor12.cbc@gmail.com
\end{abstract}


increasing and complexing the burden of care for women. Reports from the media, virtual networks, and organized civil society groups in Guatemala, Honduras, El Salvador, and Nicaragua indicate behaviors of men not helping to prevent, contain, and educate against the virus. In the whole situation there is an insufficient gender approach and almost no intersectionality and no focus on masculinities. This article analyzes the regional situation with gender lenses from the action and political reflection of the Masculinities Program, problematizing the figures and data, discussing the crisis of care and promoting the coresponsibility of men from a pro-feminist option.

Keywords: Masculinities, Care, Men's co-responsibility in care, COVID-19, Central America.

Fecha de recepción: Julio 2019

Fecha de aprobación: Julio 2020

\section{Politizando las Masculinidades desde El Salvador}

Los aportes que alimentan las reflexiones de este artículo se sitúan desde la trayectoria del programa de masculinidades (PM) del Centro Bartolomé de Las Casas (CBC) de Centroamérica, un colectivo social organizado legalmente desde El Salvador. La reflexión y análisis de género con los hombres surge en el año 2000, en el contexto de posguerra, luego de las firmas de los Acuerdos de Paz, el 16 de enero de 1992, con lo cual se puso fin a 12 años de guerra civil por la vía política. En ese contexto, CBC se suma a las organizaciones sociales que emprenden esfuerzos en materia de reconstrucción del tejido social y la atención psicosocial de la población.

Durante la década de los ochenta, en pleno conflicto, organizaciones de mujeres y feministas ligadas a los movimientos guerrilleros inician esfuerzos articulados para el empoderamiento de las mujeres, el cuestionamiento de la cultura y estructura patriarcal vigente en la sociedad salvadoreña y la participación política de las mujeres destacadas. Sin embargo, el abordaje sistemático de género con los hombres en la misma década, fue prácticamente ausente, y es sólo después de la firma de los Acuerdos de Paz que se menciona puntual y limitadamente en diferentes espacios sociales y del movimiento de mujeres.

Para los hombres articulados a la programación de CBC, el abordaje sistemático de género con varones llega de la mano de la teóloga y terapeuta holandesa Yose HöhneSparborth ${ }^{1}$, quien logra articular la necesidad de incorporar este enfoque, planteada por los movimientos sociales y de mujeres en Nicaragua y El Salvador, con un abordaje sistemático, utilizando la educación popular, las claves de los trabajos en corporalidad y la politización de la igualdad entre mujeres y hombres. Muy pronto los intereses y

\footnotetext{
${ }^{1}$ Nacida en 1946, hija de una madre holandesa y un padre alemán, emigró a los Países Bajos desde la antigua República Democrática de Alemania, donde ingresó a la comunidad de Hermanas de la Providencia. Teóloga, escritora, terapeuta y activista política, realiza trabajos en la acción psicosocial del trauma en El Salvador, Nicaragua, Chile y Colombia. https://dominicanen.nl/2017/12/ik-pas-niet-en-god-ook/
} 
metodologías, con una intencionalidad política progresista, confluyen con los esfuerzos pioneros de CANTERA ${ }^{2}$ en Nicaragua y un programa regional de la cooperación inglesa con Patrick Welsh (2001) y Xavier Muñoz.

La necesidad de realizar trabajos con hombres se convierte en una prioridad, orientada principalmente a hombres de la sociedad civil, generando las bases de lo que actualmente es la estrategia metodológica Equinoccio en masculinidades ${ }^{3}$. Esta estrategia cuenta con un enfoque político, una metodología validada y un programa establecido institucionalmente, con trabajos locales sistemáticos en Guatemala, Honduras y Nicaragua, en la región centroamericana y experiencias intensivas de formación en República Dominicana, Ecuador, Argentina, España y Chile.

\section{La emergencia de los cuidados y la COVID-19 en Centroamérica}

En el año 2020 los gobiernos de la región centroamericana iniciaban sus miradas regionales con la preocupación por la sequía en el corredor seco centroamericano, con los tradicionales problemas de coordinación y fragmentación de abordajes (CCCAD-SICA, 2020). En febrero, la CEPAL (2020) ya estimaba que al moderado crecimiento económico lo amenazaban riesgos como "la incertidumbre financiera vinculada a las tensiones comerciales, a los conflictos geopolíticos, a la desaceleración del crecimiento económico global y el riesgo de pandemias". Cuestiones en las que casi ningún actor social o de gobierno prestó atención y que terminarían siendo, para junio de 2020, los elementos de la más severa crisis sufrida regionalmente en lo que va del nuevo milenio.

La pandemia de COVID-19 ha golpeado fuertemente a la región centroamericana. Con el silencio de Nicaragua, El Salvador, Guatemala y Honduras, los países del Convenio Centroamericano de Libre Movilidad o CA-4 -en diferentes momentos, modalidades y con resultados variables- han tomado medidas legales para apoyar las acciones epidemiológicas en prevención, atención y seguimiento, aunque las cifras en aumento, tanto de contagios como de decesos, no son alentadoras. El COVID-19 llega como pandemia, antecedida por otras pandemias como la desigualdad, la violencia contra las mujeres -especialmente la feminicida- y la fragilidad democrática, situaciones en las que el CA-4 sigue estando en los peores lugares (PNUD, 2019; Global Peace Index, 2020).

También la pandemia de COVID-19 ha impactado fuertemente a los servicios públicos de salud y a la economía, históricamente feminizada, en torno a los servicios de los cuidados. Dentro de los hospitales de la región, el personal de salud está atendiendo el cuidado de los enfermos con horarios desproporcionados, contagios, falta de equipos y estrés creciente por la presión social y la separación de sus grupos familiares (Pérez Doubova, 2020). Desde el inicio, el personal de salud de los países de Latinoamérica y el

\footnotetext{
${ }^{2}$ Centro de Comunicación y Educación Popular, Managua, Nicaragua.

${ }^{3}$ Equinoccio es el nombre de la estrategia de trabajo en masculinidades de $\mathrm{CBC}$, inspirado en la espiritualidad maya y articulado a partir de una experiencia ritual de acompañamiento a los pueblos mayas en la aldea de Cocop, Municipio de Nebaj, en Quiché, Guatemala en 2006. La estrategia metodológica en masculinidades incluye el trabajo formativo con hombres y el diálogo intergenérico con perspectiva profeminista.
} 
Caribe (LAC) ha estado como primera línea de atención, expuesto a circunstancias extremas para desempeñar su trabajo, a mayor riesgo de infección, largas jornadas laborales, en muchos casos sin el equipo apropiado y enfrentando angustia, fatiga, agotamiento ocupacional, incertidumbre, dilemas éticos e inusitadamente, estigma, que se manifiesta en discriminación, violencia física y psicológica en sus lugares de trabajo, de residencia y a través de las redes virtuales.

El impacto de la pandemia de COVID-19 en los cuidados sanitarios afecta directamente a las mujeres. Nueve de cada diez personas en enfermería, en Guatemala, El Salvador y Nicaragua, son mujeres. Aunque las cifras del personal médico se han equiparado hasta casi rozar la paridad en esos países, a nivel general 4 de cada 5 trabajadores de la salud son mujeres en la región (OMS 2020), lo cual es coherente con que cerca del $70 \%$ del personal de salud a nivel mundial son mujeres, principalmente en las áreas de enfermería y obstetricia.

Hay otro segmento de personal de salud, con mujeres y hombres que no aparecen en la información estadística y que realizan labores de contacto con la población, asumiendo responsabilidades relacionadas con la organización comunitaria, educación y promoción en salud. Este personal está formado por voluntarios de la comunidad, mujeres parteras, promotoras, auxiliares de nutrición, encargadas de comedores infantiles, entre otras, quienes ofrecen su liderazgo y conocimientos al servicio de la comunidad y del sistema de salud, sin remuneración económica, siendo en su mayoría mujeres. Algunas veces este voluntariado, con funciones bien definidas, se ofrece a cambio de servicios de atención de salud. En tiempos de pandemia y confinamiento, se han sumado a estos grupos las sobrevivientes de violencia de género, quienes se organizan voluntariamente en grupos comunitarios para dar atención de consejería, apoyo y acompañamiento a quienes lo solicitan, y están en la disposición de llegar a aquellos lugares donde el personal de salud no puede hacerlo. De acuerdo a un reporte de la OMS (Boniol et al, 2019), la brecha de ingreso entre hombres y mujeres es del $28 \%$, a pesar de que las mujeres contribuyen unos tres mil millones de dólares americanos cada año a la salud global, especialmente en actividades de cuidado sin paga.

\section{Confinamiento para la mitad}

Una de las primeras medidas, verificada con cierto éxito en el triángulo norte de Centroamérica (Guatemala, Honduras y El Salvador), fue el confinamiento residencial obligatorio.

En El Salvador, "la cuarentena" comenzó el 11 de marzo como recomendación de salud pública y fue instaurada de manera obligatoria por un mes (22 de marzo al 21 de abril), medida inmediatamente seguida y aumentada con toque de queda por los otros países de la región. Esta cuarentena más estricta se instaló el mismo día que entró en vigor una ley aprobada por el Congreso autorizando al Ejecutivo a detener y confinar en "centros de contención" a las personas que violaran la cuarentena domiciliar. Hasta el 22 de abril, los centros de contención habían recibido al menos a 4.000 personas, fundamentalmente hombres, desde que la pandemia llegó al país; esa medida generó 
fuertes críticas, tanto a nivel nacional como internacional, por el hacinamiento y los presuntos abusos al interior de estos recintos. De hecho, algunos de ellos han pasado más del tiempo establecido (30 días), y sin recibir los resultados de sus pruebas diagnósticas para saber si tienen o no COVID-19.

En el pico del confinamiento a nivel mundial, en el mes de abril, más de 90 países y casi 3,900 millones de personas tenían orden de quedarse en casa, como reportó el 3 de abril de 2020 la Agencia France-Presse. Cerca de la mitad de la población ha tenido que dedicarse como "personal esencial", entre trabajadores de la salud, seguridad, transporte de emergencias y abastos, atención de farmacias y puntos de venta de alimentos, funcionariado logístico y político. Sólo la mitad de la población mundial podría mantenerse en confinamiento, mientras la otra mitad aseguraba la alimentación, la seguridad y los cuidados de la salud, convirtiendo en un lujo la atención de los cuidados para la mitad y una carga de alto riesgo para la otra. A esto se suma el porcentaje de quienes se quedan en casa, con dedicación a los cuidados domésticos. Estas medidas de confinamiento están siendo muy discutidas en sus efectos y alcances sobre la salud psíquica y física, y la economía. Han aparecido estudios que abordan exhaustivamente situaciones documentadas en varios países (López y Rodó, 2020), aunque casi ninguno incorporando variables de género, todavía.

Sin embargo, en el triángulo norte, pese a los continuos llamados por los medios y redes virtuales de "Quédate en casa", a ciertas medidas de compensación social como entrega de bonos en efectivo, a los paquetes alimenticios y a las narrativas predominantes de "la Humanidad está confinada, haz tu parte", no todas las personas pudieron confinar 0 sortearon la medida por diferentes circunstancias. Reportes anecdóticos en las redes virtuales de marzo y abril en la región mostraron regularmente a personas, mayoritariamente hombres, por las calles y sin mascarillas, en grupos de ocio en esquinas de barrios populares de las ciudades $y$, a veces, organizando actividades declaradas ilegales por las leyes de confinamiento, como partidos deportivos espontáneos, pero también conduciendo vehículos de lujo, acompañados de más personas, incluyendo un médico encontrado con dos mujeres (EDH, 2020). También se pudo ver imágenes de funcionarios, como la de los diputados salvadoreños, posando ante los medios sin ninguna medida de protección, durante la sesión plenaria aprobando la ley de emergencia por COVID-19 y las sesiones plenarias, incluso hasta el 18 de mayo.

\section{Los números de los hombres jóvenes y adultos en Centroamérica}

En Centroamérica, las cifras desagregadas por sexo y edad en torno a los casos de COVID-19, son escasas. De manera general, las estadísticas en estos países son poco precisas y confiables. La percepción generalizada es que los registros son sesgados e irreales por deficiencia o por intención de los gobiernos para no mostrar el mal manejo de la pandemia. También el limitado número de pruebas PCR (proteína $C$ reactiva) que se realizan por día y el número de casos asintomáticos que no son visibles y no cuantificados, influye en el sesgo de los datos. A lo anterior se suma los reportes de banalización de buena parte de la población, particularmente de hombres jóvenes entre 
Revista Punto Género N. 13. Junio de 2020

ISSN 0719-0417 / $109-130$

los 20 y 40 años de edad, que tanto en redes virtuales como medios comparten estrategias para eludir las medidas de bioseguridad y confinamiento, expresando burlas 0 relativizando las medidas decretadas por las autoridades sanitarias para paliar la propagación del nuevo coronavirus.

La pandemia incrementa cifras en los países centroamericanos, y desde el mes de mayo los sistemas sanitarios se han declarado al borde del colapso (EFE, 2020) y con personal médico limitado y agotado. A partir de la información disponible en las distintas plataformas de los estados centroamericanos, para mediados de junio el número de casos positivos por COVID-19 ascendió a 45.478 contagios y 1.255 defunciones (Biba, 2020). La información desagregada por sexo y edad, en las distintas fuentes consultadas, es insuficiente. Sin embargo, la tendencia general es que los hombres constituyen la mayor cantidad de contagios y muertes. Por ejemplo, el Ministerio de Salud de Guatemala (2020), citado por la OMS (2020), reportó al 18 de abril "un total de 235 casos de los cuales el $58.30 \%$ fueron hombres" y para inicios de julio el porcentaje aumentó alcanzando el 63.32\% (MSPAS 2020). El rango etáreo de mayor contagio en Guatemala se ubica entre los 11 y 40 años.

En el caso de Honduras y según los datos del Despacho de Comunicaciones y Estrategia Presidencial (2020), del total de contagios, el 55\% son hombres y del total de muertes por el virus, el $67 \%$ corresponde a hombres. El rango etáreo en el que se ubica la mayor incidencia es entre 21 y 40 años. A inicios de julio, el total de decesos por COVID19 en ese país es de 789 , de los cuales el $67 \%$ son hombres y $33 \%$ mujeres (BVS, 2020).

En El Salvador, la Procuraduría de los Derechos Humanos (2020) presentó un reporte que comprende el período 21 de marzo al 22 de abril -sobre detenciones, algunas tipificadas como arbitrarias- por parte de las autoridades, para personas que desafiaron la cuarentena, siendo en su inmensa mayoría, otra vez, hombres, especialmente entre los 30 y 59 años. El rango etáreo de contagio se ubica entre los 20 y 39 años. De los 4,808 casos de COVID-19 confirmados al 21 de junio el $61.4 \%$ corresponde a los hombres y el $35.9 \%$ a mujeres (Ramón y Argueta, 2020).

También en Guatemala, la Policía Nacional Civil (2020) reportó más de 10 mil personas detenidas por violar la cuarentena o el toque de queda, incluso interrumpiendo fiestas, con detenciones de personas "bajo efectos de licor, portando armas de fuego ilegalmente, otros estaban disparando", en su mayoría hombres. Hasta julio, se había detenido 29.827 hombres, 2.016 mujeres, 412 niños y 54 niñas.

La tendencia de contagio del COVID-19, según los datos antes expuestos, ubica a los hombres jóvenes y adultos jóvenes como la población de mayor riesgo.

\section{Los hombres jóvenes, dueños del virus}

La información circulando a nivel mundial alerta que el coronavirus SARS-CoV-2 es especialmente letal entre la población mayor de 60 años, con sistemas inmunológicos de respuesta lenta y con menor resistencia. La letalidad del virus ha mostrado ser muy 
elevada entre personas mayores residentes en instituciones geriátricas, personas con historial crónico de afecciones de diversa índole y personal sanitario. Se sabe que las personas más jóvenes presentan con más frecuencia un estado asintomático y son fuertes propagadores del virus. Aunque falta mayor armonización de las cifras y análisis comparativos en la región centroamericana, al parecer la mayoría de contagios ocurre en hombres, jóvenes, de áreas urbanas, y esta tendencia incluye los fallecimientos.

Las narrativas de los medios de comunicación alertan que los contagios no distinguen edad, raza, religión y condición social, pero depositan sobre la gente joven la responsabilidad de no transmitir el virus, porque a pesar de que no sufran condiciones de hospitalización por COVID-19, sí pueden generar un alto número de contagios. Sin embargo, estas narrativas no muestran una diferenciación por sexo y género, a pesar de que las cifras de detenidos en la región han mostrado que las personas circulando por las calles son principalmente hombres.

La debilidad de los datos estadísticos sobre COVID-19 representa un obstáculo para el análisis de la pandemia y en el diseño de estrategias de mayor efectividad para paliar la propagación del virus. Asimismo, la lectura sin lentes de género de la pandemia no permite conocer los patrones culturales que pueden estar incidiendo en la propagación de virus por parte de los hombres. Si bien es cierto en la esfera pública se ha analizado el impacto negativo del confinamiento contra las mujeres -en prácticas de violencia, feminicidios, sobrecarga doméstica y de cuidados-, también es cierto que el análisis de los patrones culturales de la masculinidad hegemónica en la emergencia son escasos y sesgados.

\section{Protestas y confrontación en las redes}

Las noticias sobre la pandemia en los Estados Unidos de América y la interacción en el tema del presidente Donald Trump han tenido un fuerte abordaje en los medios de comunicación mundiales. El impacto sobre la opinión pública centroamericana es grande, probablemente por el alto número de personas que residen, trabajan y migran en diferentes estados de la Unión americana. El presidente Trump ha tenido uno de sus más exitosos trending topic al pronunciarse a favor de no utilizar mascarilla en prácticamente toda situación, incluyendo concentraciones masivas, descalificando incluso a sus asesores más cualificados en salud. La opinión pública en aquel país está dividida entre quienes apoyan al presidente y no usan mascarilla como valientes patriotas, y quienes usan mascarilla y son vistos como ciudadanos desleales que hacen el juego a potencias extranjeras, como ha comentado Adam Tschorn (2020).

Una lógica parecida ha operado entre los presidentes hombres del CA-4: todos tienen que estar con el presidente y contra la pandemia, y quienes critican están a favor de la muerte. El presidente salvadoreño, Nayib Bukele, ha sido contundente en esta contraposición, llegando incluso hasta la amenaza y enfrentamiento público con los otros poderes del Estado. La reacción entre varios movimientos y organizaciones sociales, tradicionalmente alineadas a la izquierda del espectro partidario en la región, mostró durante los primeros dos meses una actitud que reforzaba la confrontación y 
descalificación, contribuyendo a una visión a dos bandos en la situación de pandemia, alentando discursos y explicaciones de injerencia extranjera, estrategia política de los poderes ejecutivos para arrasar con la institucionalidad democrática, cuando no una estrategia de alarma social para generar miedo y facilitar el control de los grupos de oposición. Llama la atención nuevamente la inmensa presencia de varones en estos discursos en redes virtuales, muy especialmente twitter y facebook, además de los argumentos de descalificación, misóginos, homofóbicos y racistas que se publican.

\section{Masculinidades y los cuidados}

El abordaje de los cuidados en la actual pandemia por COVID-19 se ha vuelto ineludible. No es un tema nuevo ni coyuntural. Ha sido ampliamente analizado, visibilizado y discutido por los sujetos feministas desde la acción política y la reflexión académica. Lo que representa cierto grado de novedad es el análisis desde la perspectiva de las masculinidades profeministas.

La noción de cuidados es polisémica y aunque ampliamente conocida y manejada por el imaginario social, no siempre remite a la desigualdad, a las relaciones de poder, a las estructuras económicas y las prácticas personales. Los cuidados son la precondición para el desarrollo social y económico y el ejercicio de derechos de ciudadanía. Abarca la provisión cotidiana de bienestar físico, mental y emocional a lo largo de todo el ciclo vital de las personas.

Ese pleno bienestar de las personas requiere, sin embargo, de otras personas que realizan actividades más complejas, de mayores recursos y con mayor significación por su durabilidad o permanencia. En este sentido amplio, se ha planteado que todas las personas son dependientes de los cuidados y codependiente de las demás y del entorno ambiental.

A lo largo del ciclo de vida existen etapas o situaciones de cuidados que comprometen la realización de una o más de las actividades cotidianas necesarias para la vida, como la alimentación, la higiene personal, el desplazamiento dentro y fuera del hogar, entre otras. También están implicados el ejercicio de los derechos, las condiciones materiales y subjetivas que proporcionan sentido, felicidad y realización.

En cada etapa del ciclo de vida, las funciones principales de los cuidados van variando desde la estimulación cognitiva y la socialización en la infancia hasta la búsqueda de la conservación de las capacidades y la autonomía, en el caso de las personas adultas mayores. De igual manera varían los objetivos: mientras en unos escenarios se busca asistir para lograr la autonomía -como en el caso de población con discapacidad y buena parte de la población adulta mayor- en otros se busca la estimulación temprana de las niñas y los niños para desarrollar sus capacidades.

Aunque cada día se sabe más sobre la enfermedad, los modos de contagio y la situación general que se vive en los países, incluyendo las medidas que debemos tomar para protegernos, todavía falta hablar y practicar más entre varones y en las familias 
sobre la corresponsabilidad de los hombres en los cuidados en estos tiempos de pandemia.

En la serie de podcast "Pelota al piso", activistas y académicos chilenos abordan la cuestión de los cuidados en tiempos de COVID-19, indagando con los autores de este artículo sobre cuatro dimensiones clave de la reflexión en masculinidades en la región: el autocuidado, los co-cuidados, los sociocuidados y los ecocuidados. Esas dimensiones de los cuidados son fundamentales para ver la participación de los hombres en los cuidados (Farias y Silva, 2020), y se desarrollan a continuación.

\section{El autocuidado, privatizado}

Sin lugar a dudas, el autocuidado es fundamental para los hombres, lo cual abarca todas las áreas de la vida e implica la generación de conciencia de que los cuidados cambian a lo largo de la vida.

Con autocuidado se hace referencia a todas aquellas acciones necesarias para la salud, la seguridad, el bienestar de la vida humana, para poder asumir los cuidados de seres en el propio entorno. También significa la consciencia y responsabilidad de las acciones necesarias a nivel cotidiano para que la vida sea saludable, plena y feliz. Cada persona es responsable de cuidarse y cuidar a los demás seres en su entorno. Los cuidados que cada quien necesita y cómo los hacemos van cambiando a lo largo del curso de vida. En el caso de los hombres es fundamental la conciencia de que autocuidarse se vincula con el bienestar de su entorno: las demás personas, los demás seres, el planeta. Esta conciencia de autocuidado no sólo es necesaria, sino vital, ya que sin cuidados no es posible vivir para sí ni para otras y otros.

El autocuidado incluye explícitamente la salud física, mental y espiritual, la alimentación, las condiciones y recursos para la vida y el placer. Es decir, las decisiones que tomamos, las cosas que consumimos, las relaciones que establecemos, el ejercicio físico, los riesgos que tomamos o decidimos no tomar, la rutina de hacer bien y a tiempo las cosas que necesitamos (como tomar a tiempo los medicamentos o colocarnos bien una mascarilla), el pedir ayuda, el preguntar lo que no sabemos. El autocuidado no se refiere sólo a la belleza estética, a la apariencia agradable proyectada a las demás personas 0 a las cosas que nos gustan y disfrutamos. Puede incluir lo anterior, pero el enfoque radical está en asegurar todo lo necesario para la vida, mantenerla saludable lo mejor que podemos, para ser plenos y felices.

En el umbral actual de los cuidados en el sistema capitalista, arribamos a la situación de pandemia de COVID-19 con nociones y prácticas de autocuidados individualizadas, aparentemente personalizadas y fuertemente privatizadas. Quienes tienen recursos suficientes pueden comprar condiciones objetivas para su autocuidado: tiempo, materiales de calidad, conocimientos para mejorar sus rutinas de autocuidado e incluso negociar complementos para satisfacer su autocuidado en la forma de espacios físicos, mobiliario y tecnología. Quienes no cuentan con los recursos necesarios, se ven condenados a soportar discursos que les responsabilizan por esa carencia, pero además 
a resolver cotidianamente situaciones que comprometen su salud, bienestar y vida, como la falta de agua para lavarse las manos, la escasez de espacios físicos para cultivar un territorio personal, la sobrecarga de trabajo atendiendo a otros cuidado-dependientes. En el caso de los varones, esto se resuelve muchas veces por la vía de comprometer recursos, sobrecargando en otras el autocuidado o apropiándose de recursos a través de estrategias no legales ni validadas por el sistema: evadir las medidas de contención, comisión de delito, precarización o puesta en riesgo del confinamiento.

\section{Los co-cuidados, feminizados}

Al igual que la mayoría de países en América Latina, en los de Centroamérica el comportamiento masculino con respecto a los cuidados de otras personas y a los cuidados básicos para la reproducción de su propia vida, como por ejemplo en las labores domésticas, es de no participación y poca valoración. Este comportamiento es coherente con la masculinidad hegemónica, entendida como aquella donde los rasgos considerados típicamente masculinos (control y propiedad, racionalidad, fuerza física) son llevados a su máxima expresión y se tornan en agresividad, falta de contacto con emociones y afectividad, uso de la violencia física sobre otras personas y a una negación de lo femenino, reduciendo su valor hasta el grado de complemento asimétrico.

En la región centroamericana, sin importar la edad, la presencia o no de responsabilidades familiares y el nivel socioeconómico de las personas, esta noción dominante de masculinidad no ha permitido integrar los cuidados como parte de sus mandatos y expectativas. Esto no quiere decir que ningún hombre cuide, pero -bajo esta noción hegemónica- quienes lo hacen se alejan del modelo de ser y actuar masculino, por lo que aun cuando estas prácticas existen, se mantienen en la invisibilidad o el ocultamiento, por temor a la censura de otros hombres y algunas mujeres.

El género como construcción social asigna a las personas, según su sexo, un conjunto de atributos, expectativas y normas con relativa rigidez, particularmente dentro del modelo hegemónico de masculinidad. Esas asignaciones tienen tal fuerza que se naturalizan, es decir, se perciben socialmente como parte natural, genética, en un sistema binario formado por hombres y mujeres. En la dimensión de los cuidados, se vinculan a comportamientos asignados: los hombres proveen ingresos, las mujeres cuidan la familia, y con la identidad esperada, por ejemplo, los hombres son cuidadores y valedores del exterior, la propiedad, el nombre y el honor; las mujeres son cariñosas, generosas, buenas madres y organizadoras.

Así ha ocurrido con la construcción genérica del comportamiento y de la identidad considerada femenina. La sociedad ha ido aceptando y hoy se promueve que las mujeres sean funcionales en la casa y en un trabajo remunerado fuera del hogar y, aunque más lento y en menor medida, también hay cambios del comportamiento y de la identidad masculina. Existe evidencia documentada (Holter, 2005) por ejemplo, de los países escandinavos, donde han demostrado que bajo condiciones favorables gracias al mercado laboral y la política pública, una mayoría de los hombres pueden cambiar su práctica e involucrarse de manera plena en los cuidados. Se trataría de los co-cuidados, 
es decir, las actividades de cuidados requeridas para el sostenimiento de la vida que necesitan ser realizadas en corresponsabilidad y negociadas en los ámbitos familiares, domésticos y comunitarios. Los co-cuidados incluyen los cuidados que se dan y los que se reciben, los que se generan en una relación dinámica de interdependencia.

El tiempo total de trabajo desempeñado por hombres y mujeres, especificando cantidades de trabajo remunerado y trabajo no remunerado y de cuidados, medido por las encuestas de uso del tiempo en los países de la región, evidencia que la mayor proporción del trabajo no remunerado diario de un hogar es realizado por mujeres, lo cual limita el acceso al mercado laboral y las horas diarias disponibles para el trabajo remunerado, especialmente fuera del ámbito doméstico. Propiciar un conjunto de medidas sociales y laborales que estimulen condiciones favorables para la ampliación del tiempo disponible para cuidar, por parte de los hombres, por un lado, aumentaría la oferta. El comprometer a los hombres a ser menos dependientes para resolver tareas básicas de alimentación, vestido o limpieza del hogar, reduciría la demanda de horas de trabajo femenino no remunerado. Ello, a su vez, requiere que los cuidados de otras personas y de sí mismos comiencen a valorarse como compatibles con modelos de masculinidad funcionales, no sólo en tiempos de crisis por pandemia, sino sostenibles mucho más allá de esas coyunturas y las nuevas normalidades que generará.

\section{Los sociocuidados, desmantelados}

Cuando se plantea la politización de los cuidados, el escenario más conocido e inmediato suele ser el de las políticas públicas y el de los escenarios sociales donde se ubican los gobiernos y hacedores de política como sus primeros responsables. Hablamos de sociocuidados como la conducción de las prácticas personales y colectivas de cuidados en términos de politización y justicia de género, potenciando la corresponsabilidad de hombres y mujeres en una exigencia permanente a los estados para proveer condiciones dignas y suficientes que la hagan posible, sostenible y escalable.

Dado que los cuidados son tanto un componente de la protección social como de la política activa de empleo y a los programas de empleo y empleabilidad, la calidad del servicio de cuidados que se presta tiene una vinculación estrecha con la calidad del empleo de las personas. El personal sanitario, como se ha mencionado arriba, ha tenido que desarrollar sus labores en salas deterioradas, mal equipadas, con personal reducido y sin las condiciones de seguimiento epidemiológico idóneas para los primeros rastreos de la cadena de contagios, además de ser vitoreados por la población, los gobiernos y los medios de comunicación sin mejorar sus condiciones salariales y con escasos equipos de bioseguridad.

La falta de empleo en cantidad y calidad suficiente es una problemática significativa que enfrenta la región, agravada por el cese de la actividad económica, y que se prevé crítico en los escenarios de nueva normalidad. El Pacto Mundial para el Empleo de la OIT (meta 12 del ODS8) lanzado en la Conferencia Internacional del Trabajo y firmado por Guatemala, El Salvador y Honduras (OIT, 2009) plantea la necesidad de que 
los países cuenten con medidas orientadas a superar prácticas discriminatorias en el mercado laboral y a tener en cuenta, tanto la situación de los hombres como de las mujeres, a la hora de proteger y crear empleo. El sector de los servicios de cuidados brinda la oportunidad de generar empleos y trabajo decente -es decir, trabajo bien remunerado y con protección social- mediante la protección legal, el fortalecimiento de habilidades y competencias, la certificación y la reinserción educativa en modalidades flexibles $o$ en las generadas de manera emergente, en línea y de manera virtual o con impresos a distancia, debido a la pandemia.

Las tareas de acompañar las modalidades educativas en casa son una de la larga lista de carga de cuidados que la pandemia de la COVID 19 trajo a la mayoría de mujeres centroamericanas. Muchos hombres, especialmente urbanos y en edad reproductiva, más allá de reportes anecdóticos en la redes virtuales, con fotografías de ocasión cargando niños felices o cocinando un día domingo para la familia, no han asumido la carga cotidiana de cuidados que estaba en manos de personal remunerado (ej. con las llamadas empleadas domésticas) ni el de las cuidadoras de niños y niñas (niñeras). La gran mayoría del trabajo de cuidados en las casas particulares, que implica tanto oficio domestico como asistencia y cuidados a niños/as, personas enfermas, con discapacidad y adultas mayores que lo requieren, se ha multiplicado para las mujeres, sin intromisión de las políticas públicas o los mensajes de los gobiernos llamando al confinamiento. Las empleadas que han conservado sus empleos no formales en las casas particulares, han tenido que renunciar al tiempo compartido con sus familias. Las que pasaron el confinamiento en sus casas tuvieron que renunciar a la remuneración por su trabajo.

Desde las instituciones, las dos ocupaciones en cuidados más relevantes son: las cuidadoras de niñas y niños y los trabajadores de los cuidados personales en servicios de salud, siendo la mayoría mujeres, especialmente concentradas en el servicio doméstico. En general, desde la institucionalidad en cada país (Ministerio de Educación y Ministerio de Salud), se han desarrollado servicios que buscan apoyar y orientar a las familias en la crianza de niñas y niños y en la atención a la población en situación de dependencia, pero no reemplazar los cuidados no remunerados.

\section{Ecocuidados, romantizados}

Según la visión más común de concebir la realidad, las personas se sitúan en el centro del mundo (antropocentrismo). Aparentemente, existe una gran capacidad de transformar el entorno para satisfacer las necesidades de supervivencia, desarrollo y comodidad, pero cómo se hace y cómo debería hacerse son temas distintos. Muchos estudios se han orientado a la posibilidad que la depredación de los ecosistemas, la voracidad por recursos en zonas remotas y la ampliación desmedida del umbral de habitabilidad humana, están en la base de la vulnerabilidad ante el salto de especie del virus, de animales salvajes al ser humano, al menos en sus orígenes en China y por tanto, en un riesgo previsible en un futuro cercano. Esto ha provocado una crisis medioambiental, donde se vive en un entorno más contaminado, aumentan las alergias y 
las enfermedades desconocidas, se toma medicamentos para la ansiedad y se extiende el consumo a gran escala de alimentos transgénicos.

Aunque la responsabilidad ética y por tanto política de los cuidados para el planeta son el gran desafío social, los discursos bien intencionados pero románticos respecto del planeta que nos sostiene y nos da vida, insisten en cuidarlo, protegerlo y revitalizarlo, pero demasiadas veces asignando la responsabilidad por esas tareas a individuos 0 colectividades concretas, sin visibilizar tanto las cadenas de expropiación, extracción y aniquilación de los grandes conglomerados empresariales, en las que la presencia de los hombres es abrumadora, así como la lógica estructural del sistema que depreda el planeta y que coloca a esos hombres y los valores androcéntricos como consustancial para este paradigma.

Los ecocuidados no son posibles si no hay cambios de fondo en los hábitos de producción y consumo. Si bien los varones tienen problemas en interactuar con los discursos y prácticas de los cuidados en general y de los co-cuidados en particular, la dimensión de los ecocuidados problematizando la participación de los hombres con lentes de género ha sido casi totalmente relegada.

Desde el pensamiento ecofeminista y la palabra de varias autoras y movimientos sociales pioneros en la relación de género y el cuidado del planeta, en varias partes del mundo, se están haciendo avances hacia modos de vida más respetuosos para la naturaleza, más sano para el planeta y más simple.

Cada vez más se habla del de-crecimiento o del "buen vivir", una idea que implica una redefinición de los hábitos de consumo y una disminución de la producción de residuos hasta acoplarlos a la capacidad y ritmo de producción de la naturaleza, pero las palabras, acciones e indicadores que toquen a los varones están ausentes. En general, el mundo actual aprecia la abundancia de bienes materiales, el enriquecimiento, el consumo, la producción, el crecimiento de la economía, cuestiones fuertemente valoradas por el modelo hegemónico de masculinidad. Los recursos y espacio son finitos, por eso la exigencia de cuidarlos, centrando el paradigma de sociedad que queremos, cuánto cuesta en términos de sostenibilidad ambiental y proyectando los pasos, instrumentos y consensos para enfilar hacia ese rumbo.

\section{Descuidos y contracuidos}

En el análisis de los cuidados y la participación de los hombres en tiempos de la COVID-19 en Centroamericana, emerge la necesidad de politizar algunos conceptos de la práctica de los hombres desde el cotidiano.

El temor reportado en los medios de comunicación y las redes virtuales hacia la figura del "fiestero insumiso" en tiempos de medidas sanitarias para restringir los contagios, le planta como un hombre joven o adulto, urbano, con una masculinidad muy cercana al modelo hegemónico, que actúa con descuido y participa de fiestas y actividades masivas que han sido restringidas o que exhibe públicamente su desacuerdo y no aceptación de las normas con actitudes de riesgo. "Un brote por una pequeña fiesta 
inocente puede ser el inicio de una nueva epidemia", citaban a Fernando Simón, funcionario a cargo de las acciones gubernamentales del Estado español frente a la pandemia (Zas Marcos, 2020). Estos descuidos no son referidos al olvido o postergación de algo como menos importante, sino una actitud constante en los cuidados, que implica el riesgo para otras personas y para sí mismo, la violación de normas y la percepción personal de que alguien más asumirá las consecuencias generadas por el descuido, es decir, otra persona tomará la carga de cuidados que implican los descuidos.

El descuido es una actitud que puede hacer mucho daño a las demás personas del entorno de los hombres, cargando con más responsabilidades, tiempo y recursos a las personas con las que viven y que asumen como propia la preocupación por su bienestar. Los descuidos también tienen un costo social y económico, creando una deuda con muchos intereses que tarde o temprano pasa factura, con una deuda de cuidados que llegará en salud, en bienestar de seres queridos o en infelicidad.

Muchas veces un descuido no es algo intencional, pero siempre implica la responsabilidad. Los descuidos pueden ser muy peligrosos si son intencionales y pueden llegar a convertirse contracuidados, es decir, en acciones pensadas conscientemente, de las que se sabe que van a dañar a otros y otras. La violencia de género es un ejemplo de esto último.

Poca gente con muchos recursos puede privatizar sus cuidados completamente y descuidarse de todo, algunos incluso pueden llegar a contracuidar, haciendo daño a otros y otras y al ambiente, por cuidarse a sí mismo. No es necesario ser un millonario opresor para generar descuidos o incluso contracuidar; basta con adherirse a los mandatos de la masculinidad hegemónica para participar y sostener la lógica de los descuidos y contracuidos.

\section{La construcción social de los cuidados}

En tiempos de pandemia, el perfil de la atención en los hospitales y en las casas es abrumadoramente femenino. Además del incremento de los cuidados en la salud, la COVID 19 ha enviado a millones de niñas y niños a casa por el resto del año escolar, obligando a las madres, padres y cuidadores a soportar la doble o triple carga de un trabajo a tiempo completo fuera, labores domésticas y cuidado infantil a tiempo completo, algo que, al menos, la evidencia anecdótica está sugiriendo que ha afectado la productividad de las mujeres significativamente más que la de los hombres (Viglione, 2020). Un ejemplo llamativo en esa evidencia es el enorme descenso en el envío de artículos científicos a revistas por parte de mujeres, mientras que el de hombres incrementó un 50\% (Flaherty, 2020): "Si las mujeres y los hombres están en casa, los hombres 'encuentran el modo' de hacer más trabajo académico (traducción propia)".

Como han insistido décadas de posicionamientos feministas, la sobrecarga asignada a las mujeres en los cuidados es el producto de estereotipos de género persistentes que declaran a las mujeres como más atentas, cuidadoras y generosas que los hombres. Estos estereotipos han ayudado a canalizar a las mujeres hacia trabajos 
esenciales, pero infravalorados o francamente despreciados en campos como la atención médica y la educación, y han ayudado a mantener la carga desproporcionada de atención de las mujeres en parejas heterosexuales, incluso cuando las parejas han acordado verbal y teóricamente, una división "50/50" o cuando la factura de los cuidados es asignada a otra mujer cercana (abuelas, suegras, hijas) o contratada (empleada doméstica). Tales desigualdades se han replicado de generación en generación. En realidad, la crisis doméstica y hospitalaria de cuidados que la pandemia ha develado en la región se viene incubando desde hace mucho tiempo.

En el siglo XIX, en toda Centroamérica como en casi todo el mundo occidental, el trabajo de cuidado en la salud se realizaba dentro del hogar. Cuando la gente se enfermaba, eran sus madres, hermanas, hijas, vecinas, empleadas domésticas, mujeres y niñas esclavizadas -dependiendo de si la familia era potentada terrateniente, colonos campesinos o indígenas de las montañas- quienes evacuaron los desechos bioinfecciosos (entiéndase heces, tejidos, vómitos, etc.), limpiaban las habitaciones de los enfermos, calmaban las fiebres, investigando en la tradición sobre remedios, los administraban, preparaban sopas y guisos y se sentaban durante largas horas junto a las camas observando los síntomas visibles de vida o muerte inminente. Miranda (2014) confirma:

"Sabemos por experiencia propia que a las mujeres se nos ha asignado el rol de cuidadoras en cualquiera de sus vertientes. Ya sea en el nacimiento, la crianza, la enfermedad y hasta la muerte. Durante siglos a las mujeres se les ha asignado esos trabajos, algunas veces por su posibilidad de gestar y amamantar y otras son más bien imposiciones sociales. Nosotras cuidamos a los enfermos y en muchas culturas son las mujeres quienes ungen o preparan los cadáveres" (P. 31).

Los pocos cuidados que se administraban en salud fuera del hogar eran ofrecidos por mujeres religiosas católicas, las Hijas de la Caridad (Caridad, 2019), que trabajaban sin o con escasa remuneración colectiva en instituciones de caridad, privadas o de los estados, como el Hospital Rosales (San Salvador), el Hospital San Juan de Dios (Guatemala).

\section{La corresponsabilidad de los hombres en los cuidados}

Los esfuerzos en la visibilización de los cuidados y los intentos de sensibilización para la corresponsabilidad de los hombres en tiempos de pandemia pueden tener altos riesgos para los avances ya logrados. Una estrategia amparada en estudios recientes (Capraro y Barcelo, 2020) busca motivar a los hombres a usar mascarillas, mediante la utilización de un enfoque llamado MASK, que incluye valoración de estereotipos tradicionales como protector, patriota, valiente, además del reporte de amplias ofertas de moda de mascarillas en cuadros de vaquero, dientes de tiburón o diseños de camuflaje, donde la sugerencia es utilizar el humor para rebajar el drama de la pandemia. Además de descubrir que los hombres son menos propensos a usar una máscara facial, el estudio encontró que "los hombres son menos propensos que las mujeres a creer que se verán gravemente afectados por el coronavirus" (Tschorn, 2020). 
Con todo, es posible no sólo detectar que las buenas intenciones y los intentos de sensibilización pueden terminar reforzando aquello que quieren transformar, sino retomar las experiencias documentadas en la región y en otros lugares del mundo acerca de lo que funciona mejor. Existe una buena cantidad de información bien documentada y validada sobre qué hacer y qué no hacer con los varones en situaciones de emergencia, epidemias y situaciones sociales límite, tanto a nivel mundial como de la región. Por ejemplo, Diaz-Ramö (2014), documentando las intervenciones en género y VIH y SIDA en El Salvador, encontró que:

"Cuando se habla de género en el VIH y SIDA, se centra su atención en las mujeres. Por ello, es importante reflexionar sobre los hombres y su papel en el desarrollo de género y en la erradicación del VIH y SIDA, por lo que a los participantes se les preguntó sobre el papel de las masculinidades. Muchas de las personas informantes fueron positivas al trabajo desarrollado en el campo de las masculinidades y el VIH y SIDA, algunas incluso se habían integrado en esos proyectos y en sus programas de prevención, mostrando que hay una promoción de cambios en los hombres, lo que sugiere una apertura del concepto de género y que una negociación de género está teniendo lugar desde ya" (P. 76)

Las mejores prácticas, tales como reconocer la diversidad y las distintas necesidades de los hombres, no descartar las barreras que enfrentan los hombres para acceder a los servicios y garantizar que no nos enfoquemos romántica o inocentemente en las necesidades o sufrimientos de los hombres a expensas de las mujeres, son lecciones estratégicas que pueden aplicarse en la respuesta a COVID-19.

La corresponsabilidad de los cuidados implica una reorganización, ya que en la actualidad están concentrados en manos de las mujeres de las familias, en el interior de espacios domésticos, conformando una organización de los cuidados marcadamente maternalista, es decir, que entiende los cuidados como una capacidad y una responsabilidad exclusivamente femenina. La corresponsabilidad social conlleva a visibilizar, reorganizar y valorar los cuidados involucrando a los hombres tanto en los cuidados a terceros como en su autocuidado, en un espectro que pasa por la conciencia y ejercicio de los co-cuidados, pasando por las instituciones distintas a la familia, en particular el Estado y el mercado laboral, incluyendo a sus respectivos actores - como las empresas y las organizaciones laborales-, para finalmente conectar activa y efectivamente, como bien ha quedado demostrado en asuntos globales como calentamiento global y ahora la pandemia por el coronavirus, con los ecocuidados. La reorganización de los cuidados también implica la conciencia que lleve a los hombres a desmarcarse y liberarse de la condición que impone el mandato de la masculinidad hegemónica, tal como lo plantea Rita Segato (2018), "las primeras víctimas del patriarcado son los hombres mismos, quienes deberán luchar para desmarcarse de esta determinación, no por las mujeres, sino por sí mismos" (P. 215). 


\section{Consideraciones finales}

La proliferación de artículos sobre género y COVID-19 a nivel mundial se ha centrado en el impacto en las mujeres, como la enorme carga sobre las mujeres como cuidadoras y, en la región centroamericana, en el aumento de las tasas de violencia de género, especialmente en las casas de habitación, durante el confinamiento y los toques de queda. Esta es una situación que debe ser visibilizada y abordada de manera urgente, porque muchas mujeres sufren la pandemia del COVID-19 de manera simultánea con la de la desigualdad y la violencia de género. Sin embargo, la comunidad mundial de la salud también debe abordar los riesgos de los hombres relacionados con la pandemia, e involucrar positivamente a los hombres para abordar los desafíos que enfrentan las mujeres, abordando el género como un factor determinante clave y con ello, generar beneficios para los varones.

Los crecientes informes sobre hombres y COVID-19 se han concentrado en sus tasas de mortalidad más altas que las de las mujeres, incluso asignándole un peso biológico muy grande, por ejemplo invocando diferencias biológicas entre los sexos, como hormonas y sistemas inmunes más fuertes de las mujeres, cuando todavía no hay certezas en los estudios. ¿Por qué son más altas las cifras de afectación por la COVID-19 entre los hombres? Los artículos han citado las tasas más bajas de lavado de manos de los hombres por la falta de una educación apropiada y actitud de descuido, tasas más altas de tabaquismo, afecciones subyacentes, como enfermedades cardíacas y respiratorias, todos rasgos promovidos y potenciados por el modelo hegemónico de masculinidad. Se sabe que estos comportamientos o condiciones apuntalan que, en general, los resultados de salud de los hombres en general son pobres (Etienne, 2018). La relación entre los contagios y decesos y los cuidados juega un rol muy importante en las posibles explicaciones.

Para mejorar resultados, es necesario reunir evidencia sobre las diferencias biológicas y sociales en hombres y mujeres, con perspectiva interseccional, destacando la edad, lugares de residencia y la provisión de cuidados y adaptar las estrategias de salud, incluyendo lentes de género para los abordajes específicos de las masculinidades. Ya existen muchas estrategias comprobadas para mejorar los resultados de salud de los hombres, desde cambiar las normas de género dañinas, hasta adaptar los mensajes y servicios de salud a los hombres difíciles de alcanzar. La COVID-19 presenta una oportunidad de aplicación de estrategias para transformar las desigualdades y los sistemas defectuosos que alimentan los riesgos para la salud de hombres y mujeres. Las normas de género configuran fundamentalmente la salud de las mujeres y los hombres en todas las etapas de la vida, áreas de salud y países. Los años de estudios sobre el campo del VIH y Sida han mostrado que las masculinidades dañinas generan diversos comportamientos de riesgo, como la búsqueda de salud deficiente, el abuso del alcohol y el sexo coercitivo; y llegar a los hombres a través de los servicios de salud tradicionales es inadecuado (Delgado et al, 2014).

Sin embargo, las inversiones para cambiar las normas dañinas comunes que impulsan el VIH y SIDA, en mensajes y servicios para llegar específicamente a los 
hombres, no se realizaron sino hasta varios años después de declararse como pandemia. Por los datos y fenómenos que se está observando en Centroamérica, parece evidente que durante e inmediatamente después de la situación sanitaria generada por el coronavirus, no hay tanto tiempo de espera.

Los gobiernos tienen la oportunidad de involucrar a los hombres para abordar las amenazas relacionadas con COVID-19 para la salud y el bienestar de las mujeres, incluidos los picos en los informes de violencia de género que están llegando de todo el mundo, con escalas preocupantes en la región (Taub, 2020).

Dados los servicios inundados y la movilidad limitada por los confinamientos y toques de queda, no parece que simplemente se pueda proporcionar servicios y poner la carga que amenaza la vida de las mujeres para buscar ayuda o recargar a las mismas mujeres, a la sociedad civil organizada con la tarea de generar creativamente y con pocos recursos al límite del riesgo, prácticas efectivas y rápidas; más bien, es imperativo tomar de frente la violencia en las familias y prevenir el comportamiento violento de los hombres.

Existen estrategias basadas en evidencia para esto en la región. En Centroamérica se está llevando a cabo una estrategia radial con radios comunitarias, organizaciones sociales y liderazgos locales, campesinos e indígenas, orientada a los varones rurales, jóvenes y adultos que no tienen acceso de calidad al internet, con espacios para llamar y conversar sobre la situaciones de los cuidados o su ausencia en los espacios domésticos y comunitarios presionados por el confinamiento. Esta estrategia puede adaptarse rápidamente para familias confinadas. Este momento es una oportunidad para involucrar a hombres y niños mediante la integración de actividades que no solo provean entretenimiento para mitigar el estrés y las presiones de género de los hombres, sino una reflexión crítica destacando las pequeñas prácticas y declaraciones de hombres que generan cuidados y prevención de violencia, no siempre visibles y valoradas.

Podemos trabajar con aliados existentes entre los varones comunes y corrientes para catalizar estos cambios, y no comenzando con personajes considerados populares por los medios de comunicación o que representan figuras masculinas de éxito según los estándares del modelo hegemónico de masculinidad. Hay suficiente información de que con las órdenes de quedarse en casa, el cierre de escuelas y el creciente desempleo, la pandemia está alterando rápidamente los roles de género. En todo el mundo, muchos padres que trabajan a tiempo completo desde casa ahora hacen malabares con las llamadas en conferencia sobre cuidado de niños. Las mujeres, que hasta ahora han brindado varias veces más trabajo de cuidado que los hombres en el hogar y constituyen la mayoría de la fuerza laboral de salud, sin duda están asumiendo la mayor parte del trabajo de cuidado.

Tal vez la situación de crisis de los cuidados generada con la COVID-19 es otra oportunidad para establecer políticas de trabajo flexibles a largo plazo, cambiar las ideas de los hombres como cabezas de familia y la mentalidad cambiante pero estable como 
Revista Punto Género N. 13. Junio de 2020

ISSN 0719-0417 / $109-130$

proveedor de la familia, para promover roles compartidos de corresponsabilidad de los cuidados entre mujeres y hombres.

Esta crisis puede ser diferente. En la pandemia de hoy, reconocer y promover la capacidad universal y la responsabilidad de la atención de la humanidad tiene el potencial de dar vida a cualquier cantidad de reformas, incluyendo licencia familiar remunerada, educación infantil gratuita o subsidiada y una distribución más equitativa del trabajo doméstico. La pregunta sigue siendo si realmente estamos dispuestos a colocar la justicia de género por encima de las normas tradicionales.

\section{Bibliografía}

Asamblea Legislativa de El Salvador. Disponible en: https://www.facebook.com/asamblea.legislativa/photos/a.208378966665/1015 $\underline{6843751931666}$ [Consultado 12 de mayo de 2020]

Biba, Esteban (2020). La COVID-19 se dispara en Centroamérica con cifras récord de contagios y muertes. EFE. España. Disponible en: https://www.20minutos.es/noticia/4291571/0/el-coronavirus-se-dispara-encentroamerica-con-cifras-record-de-fallecidos-y-contagiados/ [Consultado el 14 de julio de 2020]

Biblioteca Virtual en Salud (2020): Emergencia por Coronavirus (COVID-19). Honduras. Disponible en http://www.bvs.hn/php/level.php?lang=es\&component=59\&item=60 [Consultado el 14 de julio de 2020]

Boniol M, Mclsaac M, Xu L, Wuliji T, Diallo K, Campbell J. (2019): Gender equity in the health workforce: analysis of 104 countries. World Health Organization.

Capraro, V., y Barcelo, H. $(2020,1)$ : The effect of messaging and gender on intentions to wear a face covering to slow down COVID-19 transmission.Dlsponible en: https://doi.org/10.31234/osf.io/tg7vz [Consultado el 13 de julio de 2020]

Comisión Económica para América Latina y el Caribe (2020): Balance preliminar de las economías de Centroamérica y la República Dominicana en 2019 y perspectivas para 2020: febrero de 2020 (LC/MEX/TS.2020/3), Ciudad de México, CEPAL.

Despacho de Comunicaciones y Estrategia Presidencial de Honduras (2020): Coronavirus COVID-19 En Honduras. Disponible en: https://covid19honduras.org/ . [consultado el 13 de julio de 2020] 
Revista Punto Género N. 13. Junio de 2020

ISSN 0719-0417 / $109-130$

Diario El Mundo (2020): Médico del ISSS detenido con dos presuntas trabajadoras del sexo. Disponible en: https://diario.elmundo.sv/medico-del-isss-detenido-condos-presuntas-trabajadoras-del-sexo/ [Consultado el 13 de julio de 2020]

Diaz-Ramö, Liinu (2014): La deconstrucción de género, VIH y sida en El Salvador. En: Delgado, Madrigal Rajo, Núñez, Tejeda y Miranda García (comp.): Dossier. Justicia de género, plataforma regional y masculinidades. Programa de Masculinidades-Centro Bartolomé de las Casas, p.65-81. El Salvador.

EFE (2020). El Salvador se encamina al "colapso" del sistema sanitario, según Bukele. El Salvador. Disponible en: https://www.laprensagrafica.com/elsalvador/ElSalvador-se-encamina-al-colapso-del-sistema-sanitario-segun-Bukele20200503-0009.html [Consultado el 14 de julio de 2020]

Etienne, Carissa (2018). Addressing masculinity and men's health to advance universal health and gender equality. En: Revista Panamericana de Salud Pública. 42.. Disponible en: https://doi.org/10.26633/RPSP.2018.196 [Consultado el 13 de julio de 2020]

Farías, F. y Silva, H. (2020): Programa Pelota al Piso. Masculinidades y sociedad, Capítulo 6 Chile. Disponible en: https://www.youtube.com/watch?v=5FnQSJg1P20 [Consultado 25 de junio de 2020]

Flaherty, Colleen (2020, Abril 21): "No Room of One's Own. Early journal submission data suggest COVID-19 is tanking women's research productivity". Inside Highered. Disponible en: https://www.insidehighered.com/news/2020/04/21/earlyjournal-submission-data-suggest-covid-19-tanking-womens-researchproductivity [Consultado el 13 de junio 2020]

Gobierno de El Salvador (2020). Situación nacional COVID-19. Última actualización:13 de julio. Disponible en: https://covid19.gob.sv/ [Consultado el 13 de julio de 2020]:

Hijas de la Caridad (2019): Historia de la Provincia de América Central de las Hijas de la Caridad de la Provincia de Centroamérica. En: the Worldwide Vincentian Family. Disponible en: https://es.slideshare.net/mw28/historia-de-laprovincia-de-amrica-central-de-las-hijas-de-la-caridad-133240924 [Consultado el 28 de junio de 2020]

Holter, Øystein Gullvåg (2005): Can Men Do It? On Men, Caring and Gender Equality in an East/West European Perspective. En: Artûras Tereð̌kinas y Jolanta Reingardienë. Men and Fatherhood: New Forms of Masculinity in Europe. Vilnius, Eugrimas. p.114-145. 
Revista Punto Género N. 13. Junio de 2020

ISSN 0719-0417 / $109-130$

Institute for Economics \& Peace (2020): Global Peace Index 2020: Measuring Peace in a Complex World. Disponible en: http://visionofhumanity.org/reports [Consultado 28 de junio de 2020]

López, L. y Rodó, X (2020): The end of social confinement and COVID-19 re-emergence risk. Nature Human B. Disponible en: https://doi.org/10.1038/s41562-020$\underline{0908-8}$

Ministerio de Salud Pública y Asistencia Social (2020): Casos COVID-19. Guatemala. Disponible en: https://www.mspas.gob.gt/index.php/noticias/covid-19/casos.

Miranda, Gabriela (2014): Salud, género y ciencia positivista. En: Delgado, Madrigal Rajo, Núñez, Tejeda y Miranda García (comp.): Dossier. Justicia de género, plataforma regional y masculinidades. Programa de Masculinidades-Centro Bartolomé de las Casas, p.21-36. El Salvador.

OMS (2020): Guatemala: Pandemia Coronavirus COVID19. Informe de Situación No. 03. Guatemala, OMS.

Disponible en :https://reliefweb.int/report/guatemala/guatemala-pandemia-coronaviruscovid19-informe-de-situaci-n-no-03-al-18-de-abril [Consultado el 13 de julio de 2020]

Ortiz, Flor (2020): Estado de Calamidad ha dejado más de 32 mil detenidos. Disponible en: $\quad$ https://mingob.gob.gt/estado-de-calamidad-ha-dejado-mas-de-32-mildetenidos/[Consultado el 14 de julio de 2020]

Pérez Cuevas, Ricardo y Doubova, Svetlana (2020): Los retos del personal de salud ante la pandemia de COVID-19: pandemónium, precariedad y paranoia. Banco Interamericano de Desarrollo. Disponible en: https://blogs.iadb.org/salud/es/desafios-personal-salud-coronavirus/ [Consultado el 27 de junio 2020]

Procuraduría de los Derechos Humanos de El Salvador (2020): Informe sobre actuaciones policiales y militares violatorias a derechos humanos durante la emergencia nacional por Covid-19. El Salvador.

Ramón, Lilian y Argueta, Carlos Eduardo (2020): Evolución de casos del COVID-19 en El Salvador, del 14 de marzo al 21 de junio. Boletín estadístico No. 8, FUNDAUNGO. El Salvador.

Rodríguez, Margarita (2020). Cuarentena por coronavirus | "El daño ocasionado por el confinamiento será mucho mayor que cualquier daño del covid-19 que se haya evitado": Michael Levitt, nobel de Química 2013. Disponible en: https://www.bbc.com/mundo/noticias-52998830 [Consultado el 13 de junio de 2020] 
Revista Punto Género N. 13. Junio de 2020

ISSN 0719-0417 / $109-130$

Santamaría, Jaime Arturo (2019): Reseñas. Segato, Rita Laura. Contrapedagogías de la crueldad. Buenos Aires: Prometeo Libros, 2018. 142 pp. Universidad de los Andes. Bogotá.

Segato (2018) Rita Laura. Manifiesto en cuatro temas. CritiCal times, vol. 1, no 1, p. 212225.

Taub, Amanda (2020). The New York Times (6 de abril de 2020).Disponible en: https://www.nytimes.com/2020/04/06/world/coronavirus-domesticviolence.html [Consultado el 30 de junio de 2020]

Tschorn, Adam (2020). Mask shaming men won't work. Here's what will. Los Angeles Times (22 de junio de 2020). Disponible en: https://www.latimes.com/lifestyle/story/2020-06-22/masks-and-masculinitybetter-fit [Consultado el 30 de junio 2020]

Viglione, Giuliana. Are women publishing less during the pandemic? Here's what the data say. Natur, 2020, vol. 581, no 7809, p. 365-366.

Welsh, Patrick (2001). Men aren't from Mars. Unlearning machismo in Nicaragua. CIIR, London.

World Health Organization (2018). The 2018 update, Global Health Workforce Statistics, World Health Organization, Geneva.

World Health Organization (2020). Sex distribution of health workers. Disponible en: https://apps.who.int/gho/data/node.main.HWFGRP BYSEX?lang=en [Consultado el 28 de junio de 2020]

Zas Marcos, Mónica (2020): Temor al 'fiestero insumiso' este verano: las verbenas populares amenazan con escapar al control de las comunidades. Disponible en: $\quad$ https://www.eldiario.es/sociedad/temor-fiestero-insumiso-verbenaspopulares 1 6055866.html [Consultado el 28 de junio 2020] 